\title{
Reduction of Left Ventricular Epicardial Segment Length by 100\% Oxygen Breathing in Open-Chest Dogs
}

\author{
Kinji Ishikawa, Ken Kanamasa, Tetsu Yamakado and \\ RYO KATORI \\ The First Department of Internal Medicine, Kinki University \\ School of Medicine, Sayama, Osaka 589
}

\begin{abstract}
Ishikawa, K., Kanamasa, K., Yamakado, T. and Katori, R. Reduction of Left Ventricular Epicardial Segment Length by $100 \%$ Oxygen Breathing in Open-Chest Dogs. Tohoku J. exp. Med., 1982, 136 (3), 313-318-We conducted this study in order to learn whether or not oxygen inhalation reduces left ventricular size, one of the major determinants of myocardial oxygen demand. In 11 open-chest dogs, a Mercury-in-Silastic gauge was applied to measure left ventricular circumferential length while the dogs were being ventilated with either room air or $100 \%$ oxygen. Four characteristic notches were identified on the resulting length curve: $\mathrm{L}_{1}$, length at the beginning of ejection; $\mathrm{L}_{2}$, length at the end of ejection; $\mathrm{L}_{3}$, length in early diastole; and $\mathrm{L}_{4}$, length at end diastole, $\mathrm{L}_{1}$ was shortened from $24.9 \pm 10.5$ to $24.4 \pm 9.9 \mathrm{~mm}$ (a decrease of $1.4 \pm 2.1 \%$ ) by oxygen breathing, $\mathrm{L}_{2}$ was also shortened from $26.8 \pm 11.5$ to $26.2 \pm 10.7 \mathrm{~mm}$ (a decrease of $1.5 \pm 2.9 \%$ ), $\mathrm{L}_{3}$ from $17.5 \pm 4.4$ to $17.4 \pm 4.3 \mathrm{~mm}$ (a decrease of $0.7 \pm$ $2.7 \%$ ) and $\mathrm{L}_{4}$ from $17.7 \pm 4.8$ to $17.5 \pm 4.7 \mathrm{~mm}$ (a decrease of $1.3 \pm 2.4 \%$ ). These changes all disappeared when the inspiratory gas was changed from oxygen back to air. Heart rate and left ventricular end-diastolic pressure showed no significant changes but were accompanied by a slight reduction in aortic pressure and myocardial contractile force. This study demonstrated a small but consistent reduction in left ventricular circumferential length by oxygen breathing. This reduction in left ventricular size will reduce left ventricular tension and thus result in reduction of left ventricular myocardial oxygen demand when oxygen inhalation is applied to patients with ischemic heart disease. _..... oxygen inhalation therapy; myocardium; myocardial ischemia; left ventricle
\end{abstract}

The effect of arterial hypoxia on coronary circulation has been studied extensively (Berne et al. 1957; Woods and Richardson 1959). The effect of arterial hyperoxia, on the other hand, is less well understood (Daly and Bondurant 1962; Whalen et al. 1965; Ishikawa et al. 1974b). Oxygen inhalation has been applied to patients with acute myocardial infarction in hope that this might increase oxygen delivery to the ischemic myocardium (Weglicki et al. 1969). However, this has been shown to be false (Eckenhoff et al. 1947; Ishikawa et al. 1974a). Arterial hyperoxia causes vasoconstriction of the normal as well as the partially occluded coronary artery thereby further reducing perfusion (Eggers

Received for publication, June 10, 1981. 
et al. 1962). Oxygen administration, however, improved the survival rate of acute myocardial infarction in experimental dogs (Smith and Lawson 1958) and pigs (Peter et al. 1966); this fact was also proved in patients with acute myocardial infarction (Thurston et al. 1973). The beneficial effects of oxygen inhalation were further shown by improvement in myocardial lactate utilization (Ishikawa et al. 1974a) or ST changes in electrocardiograms (Maroko et al. 1975).

The previous study (Ishikawa et al. 1974a) demonstrated that improvement in lactate utilization in the ischemic myocardium accompanied a decrease in myocardial contractile force. A reduction of myocardial contractile force in the ischemic region (Ishikawa et al. 1974a, b) will decrease myocardial oxygen demand resulting in a beneficial effect. Since left ventricular size is another major determinant of myocardial oxygen demand (Sonnenblick et al. 1968), the present study was performed to elucidate whether or not left ventricular size is changed by oxygen breathing.

\section{Materials ANd Methods}

Eleven mongrel dogs, weighing between 12 and $30 \mathrm{~kg}, 17 \pm 6 \mathrm{~kg}$ (mean \pm one standard error) were anesthetized with $25 \mathrm{mg} / \mathrm{kg}$ of sodium pentobarbital while respiration was maintained by a respirator (SR-300, Acoma). The heart was exposed through the fifth left intercostal space and suspended in a pericardial cradle. A precalibrated mercury gauge (Mercury-in-Silastic, $1 \mathrm{~cm}$ in length, Parks) was sutured on the left ventricular free wall either parallel or cross to the superficial layer fiber direction of the myocardium according to Forrester et al. (1974).

A KIFA catheter, $10 \mathrm{~cm}$ in length was inserted from the apex into the left ventricular cavity to measure left ventricular end-diastolic pressure using a pressure transducer (MPU-0.5, Nihon Kohden). One min prior to each pressure measurement, the catheter was flushed with $2-3 \mathrm{ml}$ of heparinized saline to eliminate blood clots within the catheter and the zero value of the pressure transducer was adjusted before each measurement to exclude minor drifting of the pressure-amplifier-recorder system. A catheter was inserted into the femoral artery to measure arterial pressure and to obtain arterial blood samples. Aortic flow was measured using an electromagnetic flowmeter probe (MF-46, Nihon Kohden) located at the aortic root. Myocardial contractile force was measured using a Walton-Brodie type myocardial strain gauge arch (Cotten and Bay 1956) (HD-1T, Nihon Kohden). Data were recorded on an eight-channel ink-writing oscillograph (RM-85, Nihon Kohden). Using an oscilloscope (Addscope ATA-260, Nihon Kohden), 16 beats synchronized with the QRS complex of an electrocardiogram were averaged in preparing the mercury gauge curve and the left ventricular pressure curve shown in Fig. 1. Values were measured at the peak of the curve located at the early systole $\left(\mathrm{L}_{1}\right)$, at the shoulder at the end of systole $\left(\mathrm{L}_{2}\right)$, at the nadir at early diastole $\left(\mathrm{L}_{3}\right)$ and at the nadir at end-diastole $\left(\mathrm{L}_{4}\right)$ (Fig. 1). Left ventricular pressure at the beginning of the electrocardiogram $R$ wave was measured as the value at left ventricular end-diastolic pressure.

All measurements were performed during air breathing (Air). Five min after switching ventilation from room air to $100 \%$ oxygen $\left(\mathrm{O}_{2}\right)$, the measurements were repeated. As soon as the measurements using $100 \%$ oxygen breathing were completed, the inspiratory gas was switched back to room air and measurements taken a third time. Arterial blood samples were analyzed for $\mathrm{pO}_{2}, \mathrm{pCO}_{2}$ and $\mathrm{pH}$ each time (ABL 1 Radiometer).

The data were excluded if there was an alternating pulse. If either heart rate varied by more than 6 beats/min or the mean aortic blood pressure varied by more than $5 \mathrm{mmHg}$ between the initial and final air breathing values, those experiments were also discarded. 


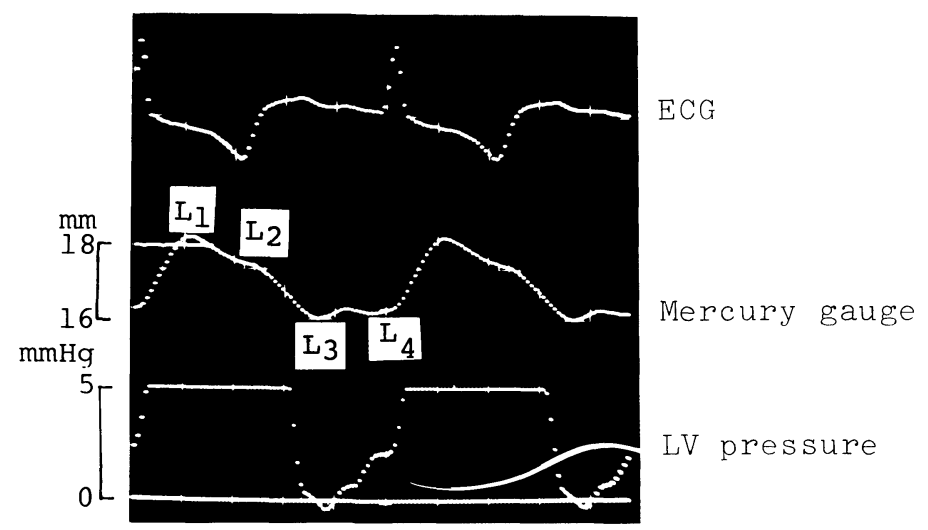

Fig. 1. The Mercury-in-Silastic gauge tracing, left ventricular end-diastolic pressure tracing at high amplification and electrocardiogram. Refer to the text for $\mathrm{L}_{1}, \mathrm{~L}_{2}, \mathrm{~L}_{3}$ and $\mathrm{L}_{4}$.

\section{Results}

Arterial $\mathrm{pO}_{2}$ was elevated from 92 to $444 \mathrm{mmHg}$ by $100 \%$ oxygen breathing (Table 1). There were slight but significant decreases in aortic pressure, aortic flow and stroke volume, but no change in heart rate.

Myocardial contractile force was decreased by oxygen breathing. There was no significant change in left ventricular end-diastolic pressure by oxygen breathing.

Maximum length at early ejection $\left(\mathrm{L}_{1}\right)$ decreased from $24.9 \pm 10.5$ to $24.4 \pm 9.9$ mm by oxygen breathing (Table 1, Fig. 2), an average reduction of $1.4 \pm 2.1 \%$. This change was reversed when oxygen was replaced by room air.

TABLE 1. Changes of segment length of the left ventricle by 100\% oxygen breathing in dogs

\section{Air}

(1)
Heart rate (beats/min)

Mean aortic pressure $(\mathrm{mmHg})$

$\mathrm{LVEDP} \dagger(\mathrm{mmHg})$

Myocardial contractile force $(\mathrm{mm})$

Aortic flow $(\mathrm{ml} / \mathrm{min})$

Stroke volume $(\mathrm{ml})$

Segment length $\mathrm{L}_{1}(\mathrm{~mm})$ $\mathrm{L}_{2}(\mathrm{~mm})$ $\mathrm{L}_{3}(\mathrm{~mm})$

Arterial blood $\mathrm{pO}_{2}(\mathrm{~mm})$ $\mathrm{L}_{4}(\mathrm{~mm})$ $\mathrm{pCO}_{2}(\mathrm{mmHg})$ $\mathrm{pH}$

$144 \pm 13$

$102 \pm 10$

$3.4 \pm 2.7$

$12.2 \pm 4.0$

$1373 \pm 688$

$9.7 \pm 5.9$

$24.9 \pm 10.5$

$26.8 \pm 11.5$

$17.5 \pm 4.4$

17. $7 \pm 4.8$

$91.6 \pm 18.0$

$36.0 \pm 5.5$

7. $424 \pm 0.105$
$\mathrm{O}_{2}$

$$
\text { (2) }
$$

Mean \pm s.E.

Air

(3)

$145 \pm 13$

$102 \pm 11$

3. $6 \pm 2.9$

12. $1 \pm 3.9$

$1378 \pm 687$

$9.6 \pm 5.5$

9. $1 \pm 5.5$

24. $4 \pm 9.9$

26. $2 \pm 10.7$

17. $4 \pm 4.3$

17. $5 \pm 4.7$

444. $4 \pm 39.1$

$34.2 \pm 7.1$

7. $409 \pm 0.101$

$24.8 \pm 10.3$

$26.8 \pm 11.4$

$17.5 \pm 4.4$

17. $6 \pm 4.7$

(2) vs. (1) (2) vs. (3)

Difference

* NS: not significant $(p>0.05)$.

$\uparrow$ LVEDP: Left ventricular end-diastolic pressure.

$\begin{array}{ll}\text { NS* } & \text { NS } \\ <0.05 & <0.001 \\ \text { NS } & \text { NS } \\ <0.01 & \text { NS } \\ & \\ <0.05 & <0.05 \\ <0.02 & <0.05 \\ <0.02 & <0.01 \\ <0.02 & <0.01 \\ \text { NS } & \text { NS } \\ <0.05 & <0.01\end{array}$


Small but consistent reductions by oxygen breathing in segment lengths measured at $\mathrm{L}_{2}, \mathrm{~L}_{3}$ and $\mathrm{L}_{4}$ were also evident, demonstrating that oxygen breathing reduces left ventricular circumferential length.

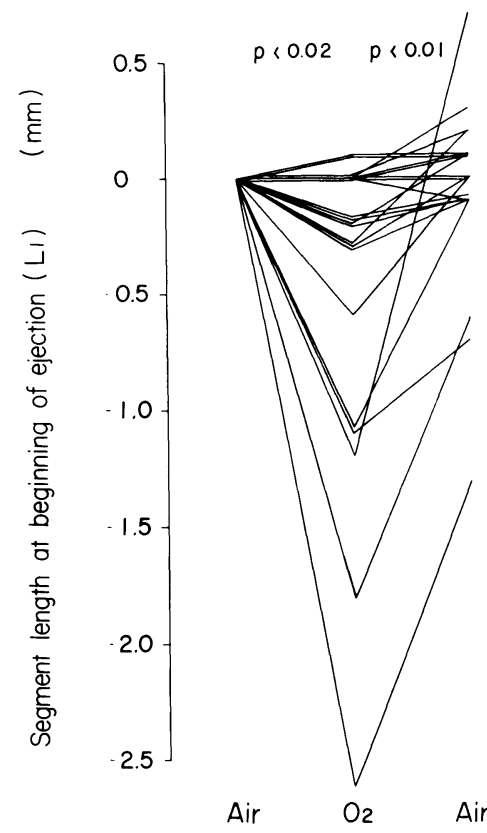

Fig. 2. Change of left ventricular circumferential segment length at the beginning of ejection $\left(\mathrm{L}_{1}\right)$ by oxygen breathing.

The value is shown as a difference from the initial value under air breathing.

\section{Discussion}

The present study indicates that left ventricular size in dogs is decreased by oxygen inhalation. This change will reduce myocardial tension and thus reduce myocardial oxygen demand (Sonnenblick et al. 1968). If oxygen is given to a patient with acute myocardial infarction, left ventricular size might be decreased. This will reduce myocardial oxygen demand in the ischemic myocardium. If myocardial oxygen demand at the regional ischemic myocardium is reduced, myocardial oxygen supply/demand balance will be shifted towards a more favorable situation, causing a protective effect upon the ischemic myocardium.

Daniell and Bagwell (1968), who sutured an isotonic gauge on the left ventricle and measured left ventricular size during oxygen breathing, found increases in the measured value but no detailed description of the method they used was given and they themselves declared that the figures did not indicate absolute values. Keys et al. (1943) reported that heart size as measured by roentgenkymography did not change by oxygen breathing. However, it is questionable whether roentgenkymography is sensitive enough to detect the small, 1 or 2 percent reductions demonstrated in the present study.

Oxygen inhalation causes a relaxation of the pulmonary vascular bed (Fishman 1976), shifting blood volume to the pulmonary circulation (Eggers et al. 1962) and may reduce the preload of the left ventricle which in turn might reduce left 
ventricular size. Since stroke volume and cardiac output were reduced bv oxygen breathing in the present study and since no changes in heart rate or in left ventricular end-diastolic pressure were shown, there might be another reason for a reduction in left ventricular size.

It is perplexing that oxygen breathing should be effective in treating ischemic myocardium even though the amount of oxygen delivered to the myocardium does not increase. Several explanations have been proposed. Ribeiro et al. (1979) reported that collateral blood flow to the ischemic myocardium was augmented when oxygen inhalation was performed. Rivas et al. (1980), however, failed to reach the same conclusion even though they used a microsphere technique similar to the method used by Ribeiro et al. (1979). Maroko et al. (1975) proposed that since oxygen constricts coronary arteries in normal tissue, there may be an increase in the pressure gradient between normal and ischemic areas, diverting more blood to the ischemic zone. This assumption seems unlikely since coronary arteries in a ischemic myocardium are constricted by oxygen administration to the same extent as in a normal myocardium (Ishikawa et al. 1974a, 1980); there may be no pressure gradient elicited by oxygen inhalation. If, by oxygen breathing the myocardial oxygen demand in the ischemic myocardium is lowered in excess of the decrease in myocardial oxygen delivery, the ischemic change will be ameliorated.

The combined effect of oxygen-induced myocardial oxygen demand reduction, caused by a decrease in myocardial contractile force, and a reduction in left ventricular size will bring about a favorable effect on the ischemic myocardium.

\section{References}

1) Berne, R.M., Blackmon, J.R. \& Gardner, T.H. (1957) Hypoxemia and coronary flow. J. clin. Invest., 36, 1101-1106.

2) Cotten, M. DeV. \& Bay, E. (1956) Direct measurement of changes in cardiac contractile force. Relationship of such measurements to stroke work, isometric pressure gradient and other parameters of cardiac function. Amer. J. Physiol., 187, 122-134.

3) Daly, W.J. \& Bondurant, S. (1962) Effects of oxygen breathing on the heart rate, blood pressure, and cardiac index of normal men-Resting, with reactive hyperemia, and after atropine. J. clin. Invest., 41, 126-132.

4) Daniell, H.B. \& Bagwell, E.E. (1968) Effects of high oxygen on coronary flow and heart force. Amer. J. Physiol., 214, 1454-1459.

5) Eckenhoff, J.E., Hafkenschiel, J.H. \& Landmesser, C.M. (1947) The coronary circulation in the dog. Amer. J. Physiol., 148, 582-596.

6) Eggers, G.W.N., Jr., Paley, H.W., Leonard, J.J. \& Warren, J.V. (1962) Hemodynamic responses to oxygen breathing in man. J. appl. Physiol., 17, 75-79.

7) Fishman, A.P. (1976) Hypoxia on the pulmonary circulation: How and where it acts. Circulat. Res., 38, 221-231.

8) Forrester, J.S., Tyberg, J.V., Wyatt, H.L., Goldner, S., Parmley, W.W. \& Swan, H.J. C. (1974) Pressure-length loop: A new method for simultaneous measurement of segmental and total cardiac function. J. appl. Physiol., 37, 771-775.

9) Ishikawa, K., Lee, T. \& Ganz, W. (1974a) Effect of oxygen on perfusion and metabolism of the ischemic myocardium. J. appl. Physiol., 36, 56-59.

10) Ishikawa, K., Sarma, R., Getzen, J.H., McNair, J.D., Cosby, R.S., Buggs, H., Johnson, J.L. \& Bing, R.J. (1974b) Reduction of myocardial contractility by $100 \%$ oxygen in patients with coronary disease. Proc. Soc. exp. Biol. Med., 145, 99-102. 
11) Ishikawa, K., Kanamasa, K., Yamakado, T., Kohashi, Y., Kato, A., Otani, S., Hayashi, T. \& Katori, R. (1980) Increases in coronary vascular resistance related to high arterial oxygen tension in dogs. Jap. Circulat. J., 44, 749-754.

12) Keys, A., Stapp, J.P. \& Violante, A. (1943) Responses in size, output and efficiency of the human heart to acute alteration in the composition of inspired air. Amer. J. Physiol., 138, 763-771.

13) Maroko, P.R., Radvany, P., Braunwald, E. \& Hale, S.L. (1975) Reduction of infarct size by oxygen inhalation following acute coronary occlusion. Circulation, $\mathbf{5 2}$, $360-368$.

14) Peter, R.H., Rau, R.W., Whalen, R.E., Entman, M.L. \& McIntosh, H.D. (1966) Effects of hyperbaric oxygenation on coronary artery occlusion in pigs. Circulat. Res., 18, 89-96.

15) Ribeiro, L.G.T., Louie, E.K., Davis, M.A. \& Maroko, P.R. (1979) Augmentation of collateral blood flow to the ischemic myocardium by oxygen inhalation following experimental coronary artery occlusion. Cardiovasc. Res., 13, 160-166.

16) Rivas, F., Rembert, J.C., Bache, R.J., Cobb, F.R. \& Greenfield, J.C., Jr. (1980) Effect of hyperoxia on regional blood flow after coronary occlusion in awake dogs. Amer. J. Physiol., 238, H244-H248.

17) Smith, G. \& Lawson, D.A. (1958) Experimental coronary arterial occlusion: Effects of the administration of oxygen under pressure. Scot. med. J., 3, 346-350.

18) Sonnenblick, E.H., Ross, J., Jr. \& Braunwald, E. (1968) Oxygen consumption of the heart. Newer concepts of its multifactorial determination. Amer. J. Cardiol., 22, 328-336.

19) Thurston, J.G.B., Greenwood, T.W., Bending, M.R., Connor, H. \& Curwen, M.P. (1973) A controlled investigation into the effects of hyperbaric oxygen on mortality following acute myocardial infarction. Quart. J. Med., 42, 751-770.

20) Weglicki, W.B., Rubenstein, C.J., Entman, M.L., Thompson, E.K., Jr. \& McIntosh, H.D. (1969) Effects of hyperbaric oxygenation on myocardial blood flow and myocardial metabolism in the dog. Amer. J. Physiol., 216, 1219-1225.

21) Whalen, R.E., Saltzman, H.A., Holloway, D.H., Jr., McIntosh, H.D., Sieker, H.O. \& Brown, I.W., Jr. (1965) Cardiovascular and blood gas responses to hyperbaric oxygenation. Amer. J. Cardiol., 15, 638-646.

22) Woods, E.F. \& Richardson, J.A. (1959) Effects of acute anoxia on cardiac contractility. Amer. J. Physiol., 196, 203-206. 